Economies of Scale, Natural Monopoly, and Imperfect Competition in an Experimental Market Author(s): Charles R. Plott, Alexandre Borges Sugiyama and Gilad Elbaz

Source: Southern Economic Journal, Vol. 61, No. 2 (Oct., 1994), pp. 261-287

Published by: Southern Economic Association

Stable URL: http://www.jstor.org/stable/1059976

Accessed: 03/03/2014 18:33

Your use of the JSTOR archive indicates your acceptance of the Terms \& Conditions of Use, available at http://www.jstor.org/page/info/about/policies/terms.jsp

JSTOR is a not-for-profit service that helps scholars, researchers, and students discover, use, and build upon a wide range of content in a trusted digital archive. We use information technology and tools to increase productivity and facilitate new forms of scholarship. For more information about JSTOR, please contact support@ jstor.org. 


\title{
Economies of Scale, Natural Monopoly, and Imperfect Competition in an Experimental Market*
}

\author{
CHARLES R. PLOTT \\ California Institute of Technology \\ Pasadena, California
}

ALEXANDRE BORGES SUGIYAMA

University of Arizona

Tucson, Arizona

GILAD ELBAZ

IBM Corporation

San Jose, California

\section{Introduction}

This paper reports on the behavior of markets in which all agents have identical costs with economies of scale over the entire range of demand. Each firm, by choosing a larger scale of plant and a larger volume, can experience lower average cost. Thus, the markets are characterized by the fundamental technological property that has motivated decades of theorizing about natural monopoly and imperfect competition. The primary question posed by the research is whether or not a natural monopoly emerges and sets prices at monopoly levels, or whether the data are more closely approximated by some alternative model of imperfect competition, such as monopolistic competition, Cournot oligopoly, or contestable market theory.

Some of the principle results of the experiments reported here can, in retrospect, be interpreted as having been anticipated by the pathbreaking work of Coursey, Isaac, Luke and Smith [1, 69-84], and by Coursey, Isaac, and Smith [2, 91-113]. While these previous experiments involved economic environments that were much less complicated than the one studied here, the tendencies previously observed are clearly present in the behaviors reported here. So, in a sense, the results reported here can be interpreted as a major extension of the previous results, as well as replication and robustness check.

The similarities of experimental design with previous experiments rest on the facts of falling average cost and no barriers to entry that existed in all experiments. However, the number and

*This paper began with a project in an experimental economics class at Caltech in which G. Elbaz and A. Sugiyama were undergraduate students. In addition to the authors, Peter Ying contributed to the project during the initial stages of research. The comments of William Novshek are also appreciated. The financial support of the National Science Foundation and the Caltech Laboratory for Experimental Economics and Political Science is gratefully acknowledged. 
nature of departures from the previous research are substantial. The markets studied here were much larger, so parameters took values in a more continuous manner. The experiments studied here involved two markets, so entry into the falling average cost market was accompanied by the opportunity cost of profits foregone in the alternative market. The alternative market was a computerized double auction which agents generally enjoy, so entry into the falling average cost market did not result from an attempt to relieve boredom, which one might have suspected played a role in previous studies. Agents entering the falling average cost market were required to make a choice of scale of plant that affected costs. Thus, the theory of cost minimization played an active role in developing models. This dimension was completely absent from previous experiments. Previous experiments used linear average costs that fell with volume until a capacity constraint was reached (within the range of demand) and then costs became vertical. Average costs in the experiments reported here were nonlinear and fell throughout the range of demand. In addition, the nonlinearities, scale economies, and demand were configured to create Cournot equilibria in the appropriate Cournot model of the environment. The Cournot equilibria were separated from the competitive (price equals average cost plus opportunity cost) equilibrium. In previous experiments the Cournot equilibrium was also the competitive equilibrium. The number of potential entrants used in previous experiments was small, ranging from two to four. In the experiments reported here, there were seven potential competitors. Briefly put, the choice of parameters for the experiments reported here was such that the economic environment was similar to those commonly found in the figures in economics textbooks.

\section{Experimental Environment, Design and Procedures}

A total of three experiments were conducted. Subjects were students at the California Institute of Technology and summer interns at Caltech. Some of the subjects were experienced in the operation of electronic markets. As it turns out, the empirical tendencies that were observed in the experiments are so pronounced that only three experiments appear to be needed to answer the original question posed. Since the experiments are expensive in terms of time and money, a decision was made to limit the number of experiments to three. Given the behavior exhibited by the twenty-one people studied, the expectation that anything would be learned from additional replications seems too low to justify the cost.

Each experiment consisted of 7 buyers and 7 sellers. Subjects with experience were placed in the more complex role of sellers. Two markets were created. They will be called market A and market B. The buyers could participate in both. Sellers could participate in either but not in both. In market A sellers had identical cost functions designed such that they were guaranteed a rent from participating in the market. The parameters were chosen such that in market $\mathrm{A}$ the rents per seller and the market price were (theoretically) independent of the number of sellers that chose to sell in that market. Market A was organized by a (computerized) double auction that fully occupied the attention of the sellers that chose to function in that market so they would not be motivated by boredom to enter market $\mathrm{B}$.

Market B was different. Sellers that chose to operate in market B made irrevocable decisions about scale of plant, the quantity that they would offer for sale and the price they would post. Thus, the market organization was the standard posted price environment in which commitments were private information until the market opened. The only difference was that a seller could choose to drop out of the market once the decisions of other sellers were public but before 

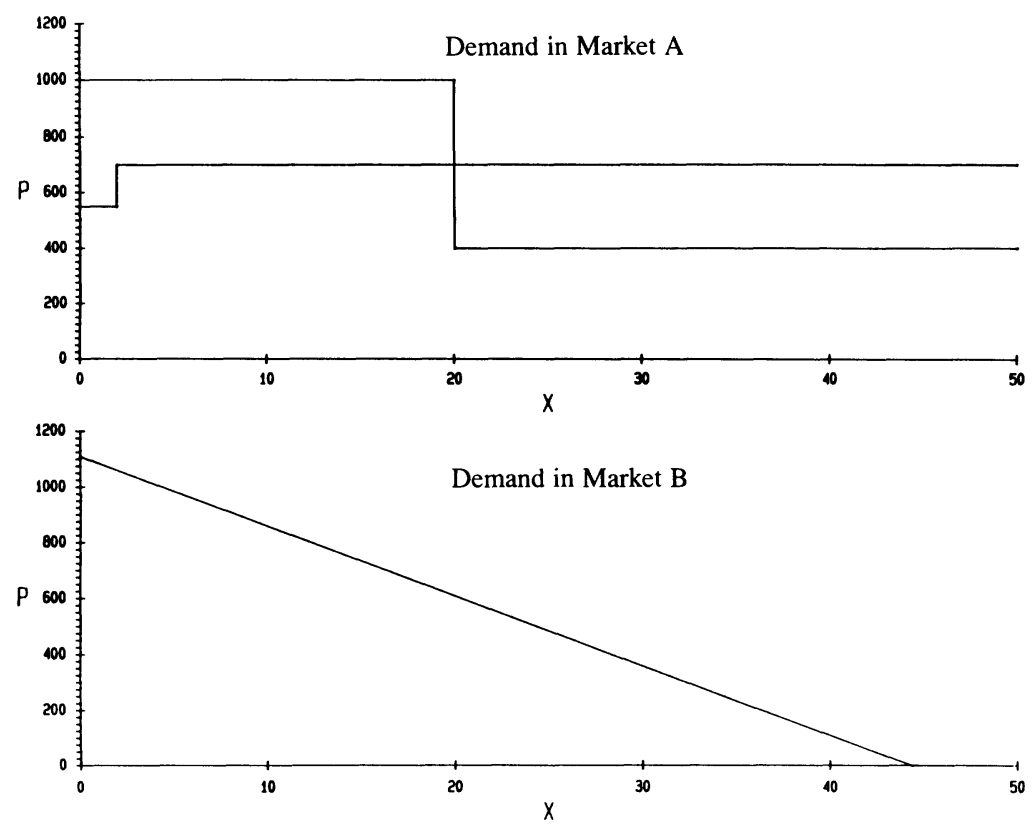

Figure 1.

the market opened. The decisions to drop out were also private (revealed simultaneously) and irrevocable. The dropout decision served to limit losses to the opportunity cost of market A profits foregone, and reduced the probability that subject bankruptcies would disrupt the experiment. In market B all sellers had the same cost function. The cost function was characterized by economies of scale.

In summary, the economic environment had the following properties:

1. Participation in market $\mathrm{B}$ involved an opportunity cost because reasonably predictable rents could be gained from participation in market $A$.

2. Participation in market A was "fun" in the sense that many people enjoy the speed and activity of the computerized double auction.

3. Participation in market B could be done without exposure to a major out-of-pocket loss. Sellers could "drop out" if they expected volume to be less than was anticipated at the time that scale of plant was chosen.

4. All transactions took place in a currency called francs. Each franc was converted to dollars at a rate of .0075 for buyers and .006 for sellers.

\section{The Market Environment}

A continuous approximation of market demands for markets A and B are contained in Figure 1 . The equation for the continuous approximation of the market demand in market $B$ is

$$
P=1110-25 x
$$

Individual parameters for the demanders are in Table I. Each of seven demanders made money by participating in market A and in market B. Each buyer had the same redemption values 
Table I. Individual Incentives

\begin{tabular}{lccc}
\hline & \multicolumn{2}{c}{ Market A } & Market B \\
\cline { 2 - 4 } Unit & Demand* & Costs** & Market Demand*** \\
\hline 1 & 1000 & 550 & 1085 \\
2 & 1000 & 550 & 1060 \\
3 & 1000 & 700 & 1035 \\
4 & 400 & 700 & 1010 \\
5 & 400 & 700 & 985 \\
6 & 400 & 700 & 960 \\
7 & 400 & 700 & 935 \\
8 & 400 & 700 & 910 \\
9 & 400 & 700 & etc. \\
10 & 400 & 700 & -25 each unit \\
11 & 400 & 700 & - \\
12 & 400 & 700 & - \\
13 & 400 & 700 & - \\
14 & 400 & 700 & - \\
15 & 400 & 700 & - \\
16 & & & - \\
17 & & & - \\
18 & & & - \\
19 & & & - \\
\hline
\end{tabular}

*All buyer agents ( 00 through 06 ) had the same demand as listed here.

**All seller agents ( 07 through 13 ) had the same costs as listed here.

***Individual agents demand rotated each period

in market $\mathrm{A}$ each period. That is, in market $\mathrm{A}$ both the market demand and the individual redemption values were constant over periods. In market $B$, the market demand was constant over periods but the redemption value of each individual changed from period to period. A fixed family of schedules was rotated among the individual demanders. The rotation schedule is contained in Plott, Sugiyama, and Elbaz [8]. The rotation convention was used because uncertainty about which model might be most accurate gave us little confidence in our ability to predict incomes of buyers. We wanted the income of all subject buyers to be sufficiently high to keep their interests. The rotation had a useful feature of removing dramatic asymmetries. Each of seven sellers had identical costs throughout the experiment. The fact that the costs were identical was not known by any agent in the markets. Each had the option of participating in either market A or in market B, but not in both. A seller that participated in market A used the cost schedule in Table I. For a single seller the graph of the (marginal) costs are included in Figure 1. As can be seen, the seller had two low cost units and then had constant cost afterwards for enough units to satisfy the entire demand.

Given these individual costs in market $\mathrm{A}$, the market price (according to the competitive model) will be constant at 700 at all volumes near the demand (at 21 units) regardless of the number of suppliers in market $\mathrm{A}$. As will be stated more clearly below, the equilibrium price will be near 700 and rents for all sellers in market $A$ will be about 300 ( 2 units at $150=700-550$ each) regardless of the number of other sellers in market $A$, as long as there are at least two.'

The costs of all seven suppliers were the same for market B. Each subject had separate tables

1. Typically, two or three sellers are enough for competitive equilibrium behavior in a double auction market. 
(in different colors) for marginal cost, average cost, and total cost. The total cost table is shown as Table II. As can be seen, costs depended upon both scale of plant and volume of sales.

A continuous approximation to the underlying discrete parameter cost function has been useful in the development of behavioral predictions, as well as experimental design decisions. Figure 2 contains a graph of the long-run average cost curve in this continuous model, and also the short-run average costs for selected scales of plant. A continuous approximation of the market demand curve is imposed over the average cost for comparison.

The formula for the competitive model is as follows. The model is restricted to the values of parameters in the range of the tables of costs. The model begins with short-run average cost (SRAC) which depends upon output and the scale of plant $(x, s)$. In the discrete values of costs in the table the scale of plant is indicated by letters of the alphabet, starting with the letter A. In the continuous model, if scale is A then $s=11$; if scale is B then $s=12$, etc., with a change of one in $s$ as the letters change:

$$
\operatorname{SRAC}(x, s)=3 / 4(x-s)^{2}+1 / 4(s-40)^{2}+300 .
$$

The optimum scale of plant given a quantity $x$ is indicated by $s^{*}(x)$. The formula is

$$
s^{*}(x)=10+3 / 4 x
$$

Substituting (3) into (2), the long-run average cost function, LRAC $(x)$ is obtained.

$$
\operatorname{LRAC}(x)=\operatorname{SRAC}\left(x, s^{*}(x)\right)=600-15 x+3 / 16 x^{2} .
$$

Of course this yields the long-run total cost (LRTC) and the long-run marginal cost (LRMC) as follows:

$$
\begin{aligned}
\operatorname{LRTC}(x) & =600 x-15 x^{2}+3 / 16 x^{3} \\
\operatorname{LRMC}(x) & =\partial \operatorname{LRTC}(x) / \partial x=600-30 x+9 / 16 x^{2}
\end{aligned}
$$

The continuous model will be very useful to the interested reader. The complicated calculations for the equilibria of various models were first done in the context of the continuous model. The location of the equilibria in models based on discrete parameters was always nearby.

\section{Market Organization}

Market A was a computerized double auction. Market B was a posted price market. Both markets opened at the same time for trading. Sellers were informed about the market demand function in market B but they knew nothing about the market demand function in market A. Since market A followed standard procedures for MUDA markets, ${ }^{2}$ only the timing and the details of market B need to be reviewed.

Before each period all seller agents were required to decide which market they would enter. After deciding they (privately) drew a large $\mathrm{X}$ through the record sheet of the market not chosen. Agents choosing market $\mathrm{B}$ would then fill in the blanks on their record for the period committing

2. See Plott and Gray [6, 245-58] for a detailed description of this market, or see Plott [5] for a description of the computerized version. 


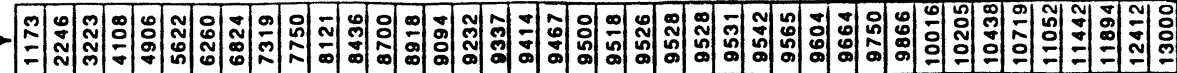
$\times$ พจิ స N

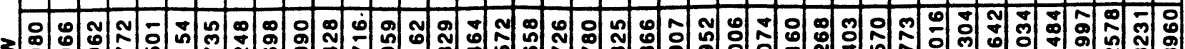

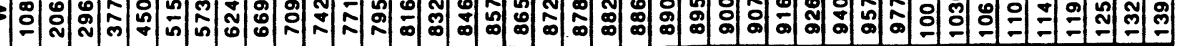

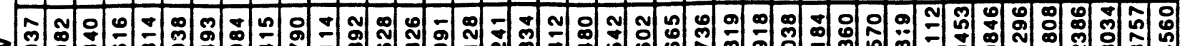

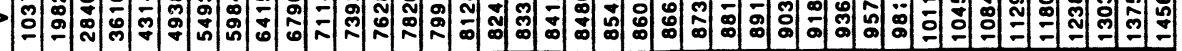
ว

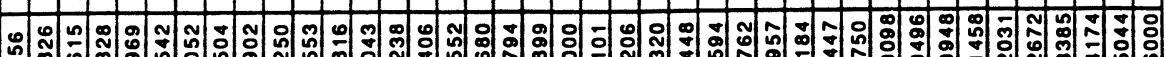
๙

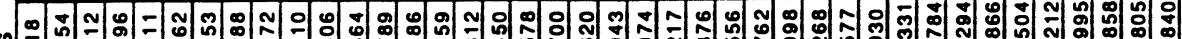

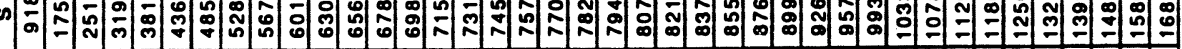

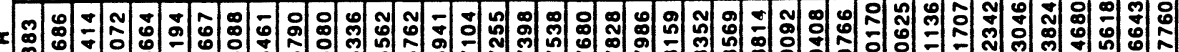

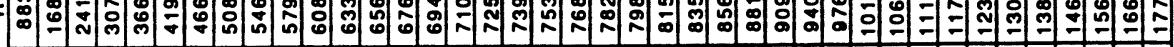

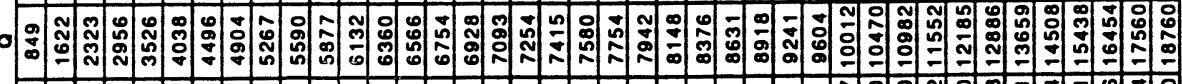

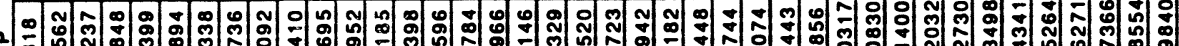

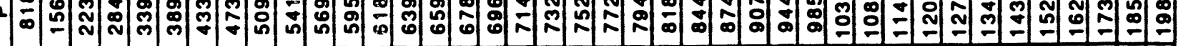

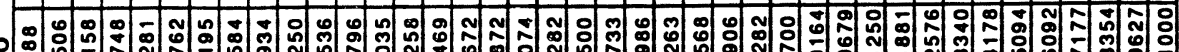

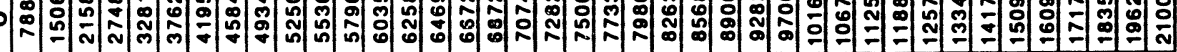
-

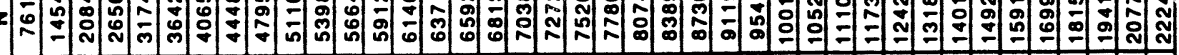

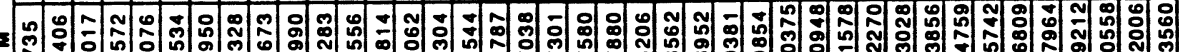

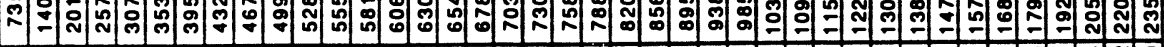

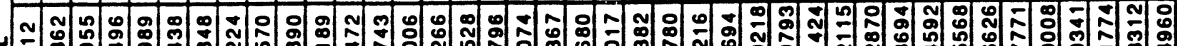

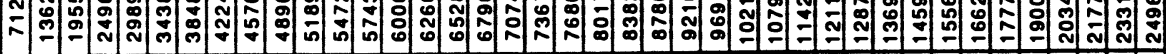

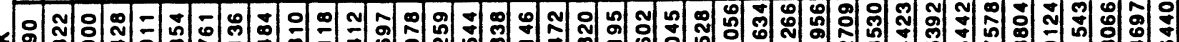

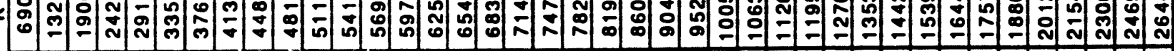

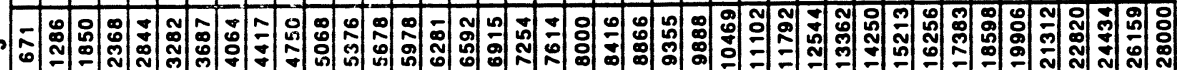

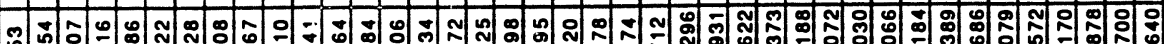

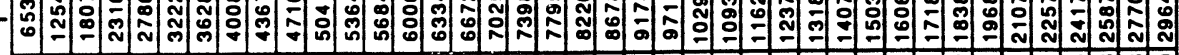

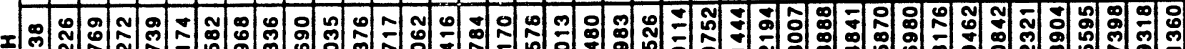

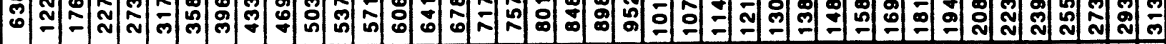
จ $จ$ จ

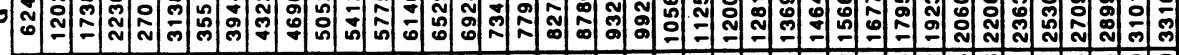
- กำจ

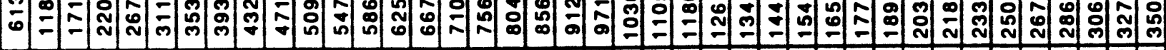

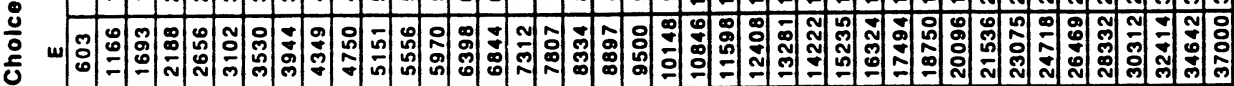

- $-\circ$ -

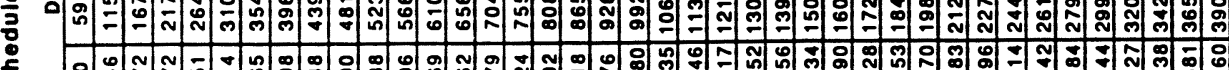

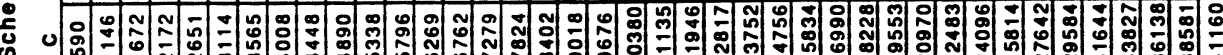

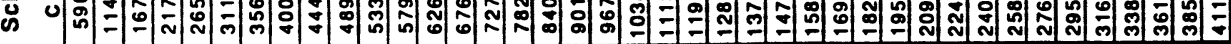

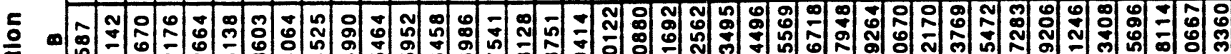
ธิด

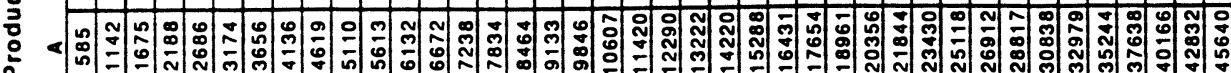

-

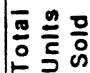




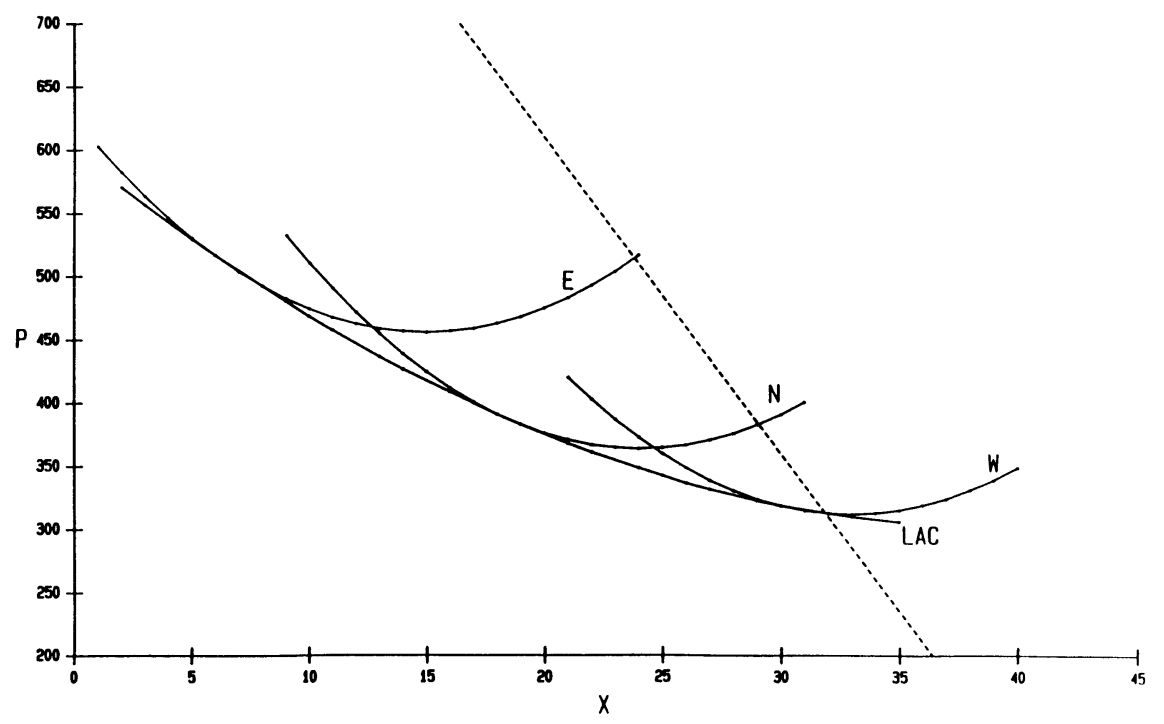

Figure 2. Long-Run Average Cost, Selected Short-Run Costs and Market Demand

themselves to a scale of plant, a quantity to be offered, and a price. The computerized MUDA program allows the simultaneous operation of multiple markets. Each of the seven sellers was assigned to a "personal market" in which no other seller could participate. The sellers would enter their (price, quantity) pairs in an order box fixed on their individual markets. At the appropriate (public) signal each seller would press the enter key, thereby making their private decisions public to all buyers and sellers as they were displayed by the computer as asks (to sell) in their individual markets. Once sellers had seen the asks of other sellers, they had the opportunity to cancel their own asks. This was done simultaneously on signal. Sellers canceling asks were not permitted to enter the A market. They did nothing for the remainder of the period. Thus, sellers who entered market $B$ and canceled experienced the opportunity cost of A profits.

After sellers who had made the decision to enter market B had the opportunity to cancel, all markets opened for trading. Market A proceeded along the standard lines for the computerized MUDA. In market B, sellers who remained each had a price posted and a maximum quantity. At any time during a period buyers could toggle to any of these markets and purchase the number of units desired at the posted price, up to the amount for sale that the seller had left. Buyers could only accept the asks in these markets. That is, they could not tender bids in any market except market A.

A comment about the organization is in order. Market A was a double auction and it existed as a source of income and entertainment for those who chose not to enter market B. Market B was a posted price market because it is thought to provide the best circumstances for monopoly behavior [10, 83-106]. When the demand function is known, and prices are posted, the seller is most likely to successfully charge monopoly prices. Double auctions are known to have strong tendencies to converge to a competitive equilibrium even in the presence of monopoly. If market B had been a double auction, then any tendency to converge to a competitive equilibrium could have been attributed to the market microstructure alone, as opposed to the industrial organization. Thus, the posted price institution was thought to be a more favorable environment for the emergence of monopoly pricing than the double auction. 
The cancellation property is important as a risk reduction feature in this type of market. If a seller chooses a large scale of plant and succeeds in selling only a few units, large losses can be experienced. Buyers have the capacity to punish high-priced sellers by purchasing only a unit or two. Similarly, well-meaning buyers who want to share the volume by spreading purchases over sellers can be very costly to a seller who does not otherwise get the volume. Likewise, accidental purchases can be very costly. Cancellation allows those sellers who choose relatively high prices the opportunity to avoid such risks.

The experiment contained one other special feature. A market demand function for market B was privately distributed to the sellers on a sheet of paper. All sellers knew what it meant. The demand function given sellers was actually 10 francs below the actual induced values. Buyers typically do not trade without a small profit margin for themselves. We believed that the function we gave them was a better model of what they would experience than would be the actual limit values.

\section{Procedures}

The experiments were conducted in the Laboratory for Experimental Economics and Political Science at Caltech. Subjects consisted of undergraduates, graduate students at the California Institute of Technology, plus high school students who were attending a special summer program. Most had previous experience in some type of computerized market. All had paged through a computerized instruction routine that familiarized them with key functions and the mechanics of making bids, offers, and acceptances.

In addition to the three experiments reported here, pilot experiments were conducted. The pilot experiments were discarded because they typically involved choices of parameters that were based on a miscalculation of the theoretical models. The parameters and procedures of one experiment were exactly like those reported in this paper but the data are not reported because one subject evidenced substantial confusion. The results of these unreported experiments appeared qualitatively similar to the experiments that are reported here. Space constraints effectively preclude their publication. Should anyone want to study them in detail, the data will be made available upon request.

Experimental sessions which lasted on the order of three hours began in the evening at about 7:00 P.M. The detailed instructions that were read to the subjects are contained in Plott, Sugiyama, and Elbaz [8]. In addition, the material presented on the chalkboard and the step-bystep procedures for conducting the experiment are also included.

The highlights of these experimental procedures are as follows. Subjects were paid a "show up" fee of $\$ 5.00$ if they were extras and were turned away from participation. Subjects agreed to work off any losses incurred during the experiment at a rate of $\$ 10.00$ per hour. Of course, buyers could make no losses unless they resulted from some sort of (foolish) speculation or from a typo. Contracts involving obvious typos that would result in large losses were always voided by the experimenter (a standard practice). However, sellers could make a loss. If a seller entered the B market at a substantial scale of plant and sold only a small number of units the losses could be considerable.

Sellers who wanted a sure return could participate in the A market. The design of this market was such that a rent of $\$ 1.80$ per period was almost certain for participation in market $A$ and the seller was exposed to no possibility of a loss. On average, each participant made approximately $\$ 30$ from the experiments. 
Each seller was provided cost schedules for market A sales. ${ }^{3}$ For market B each seller had color-coded tables that gave marginal cost (pink), average cost (green), and total cost (yellow), of combinations of volume and scale of plant on 11 by 14 sheets of paper. Scale of plant could take 24 values, labeled $A$ through $Y$.

Two practice periods were conducted. The parameters were the same as those that were used in the experiment. The mechanics of the experiment were very complex and many questions were prompted during these sessions. The answers to all questions were given publicly in a form that yielded no information about parameters that was not already public. After each period, for the first five periods (including the two practice periods), the accounting of each subject was checked and spot checks were made throughout the experiment.

\section{Models}

Ten different types of models can be applied to the economic environment. Of course these models share many basic principles but they also differ in many ways. Some give sharp predictions and the others remain vague. Where possible the models will be applied directly to the environment in a technical, mathematical fashion. Speculations and theorizing about which model might be expected to fit the data best are not considered to be part of the exercise at this stage of the experimental inquiry. Table III contains a summary of the predictions for those models for which predictions can be computed. The paragraphs below will briefly describe each model listed in the table.

A note on efficiency may be useful, especially for those who are not familiar with experimental economics. The measure invented by Plott and Smith [7, 133-53] is a direct adaptation of consumers' and producers' surpluses. The buyers receive franc redemption values from the experimenter that can be modeled as a (derived) demand function. The total value of francs redeemed by buyers is like the gross benefits to buyers from the units they acquired. Sellers pay francs to the experimenter for units sold. These payments are costs. The allocation that maximizes gross benefits minus costs is the most efficient. It is the one that maximizes franc earnings of subjects (exhausts all possible gains from exchange). Actual franc earnings divided by the maximum possible is the efficiency with which the system is operating.

Under ordinary modes of organization, 100 percent efficiency of operation is thought to be unattainable in the downward sloping average cost case. If a single price is charged, and if price is equated to marginal cost, then sellers would lose money. This degree of inefficiency is thought to be structural in the falling-average cost case.

Other practical sources of inefficiency exist. Tough bargaining sometimes results in failures to trade. Suppliers might choose the "wrong" scale of plant and thereby impose more costs on the system than necessary. Suppliers might choose to enter the B market and then cancel. The efficiency loss would be due to the opportunity cost of the low cost units that such suppliers could have delivered to the A market. Suppliers might choose an unnecessarily limiting quantity of $x$ offer to the market B. In the section on models the efficiency of the equilibria allocation predicted

3. Rounding errors caused slight discrepancies between these schedules. For example, total cost at the contested market equilibria of scale $W$ and volume 31 was 9765 , if computed from the average cost table, and it was 9773 as listed on the total cost schedule, a difference of 4.8 cents. 


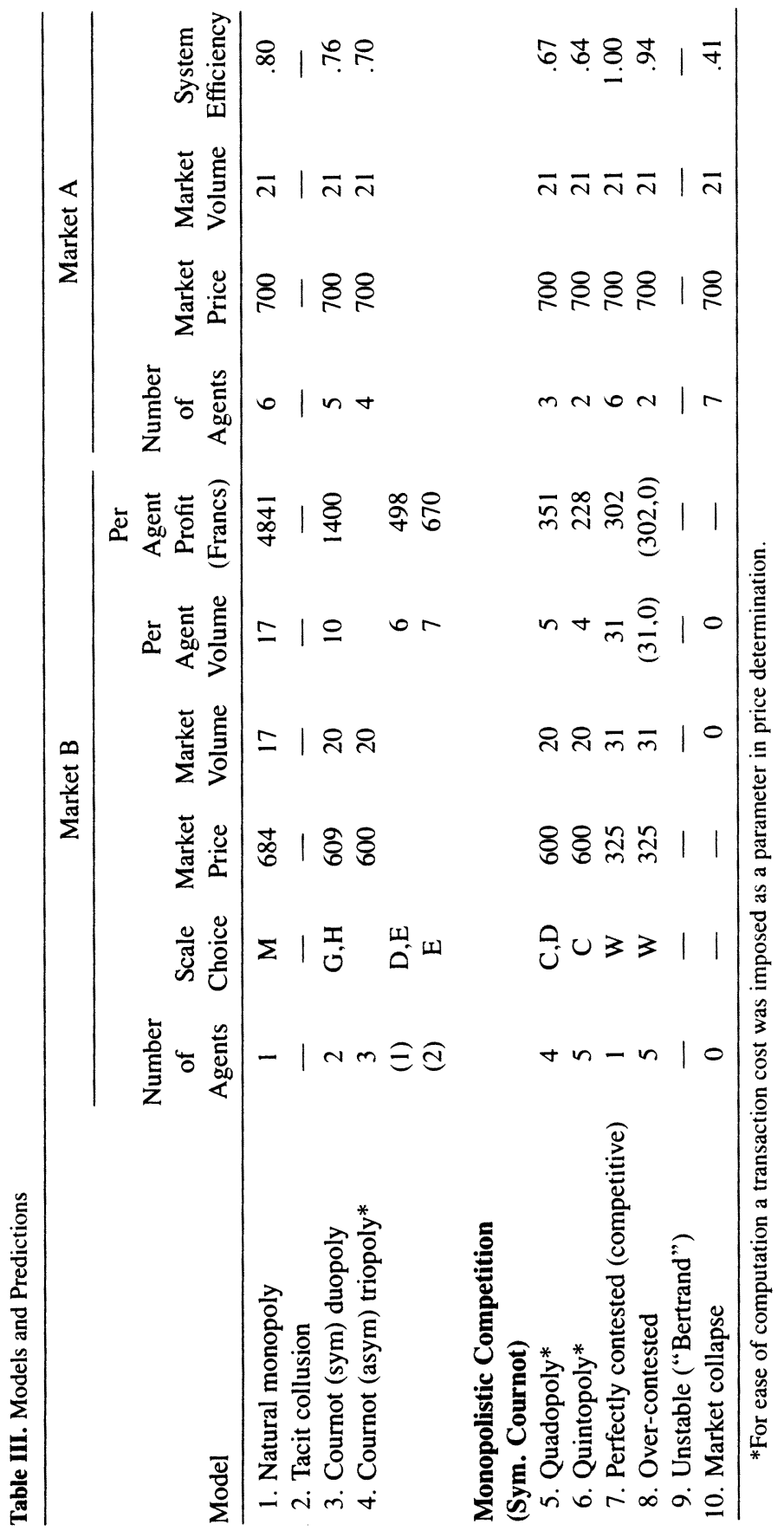




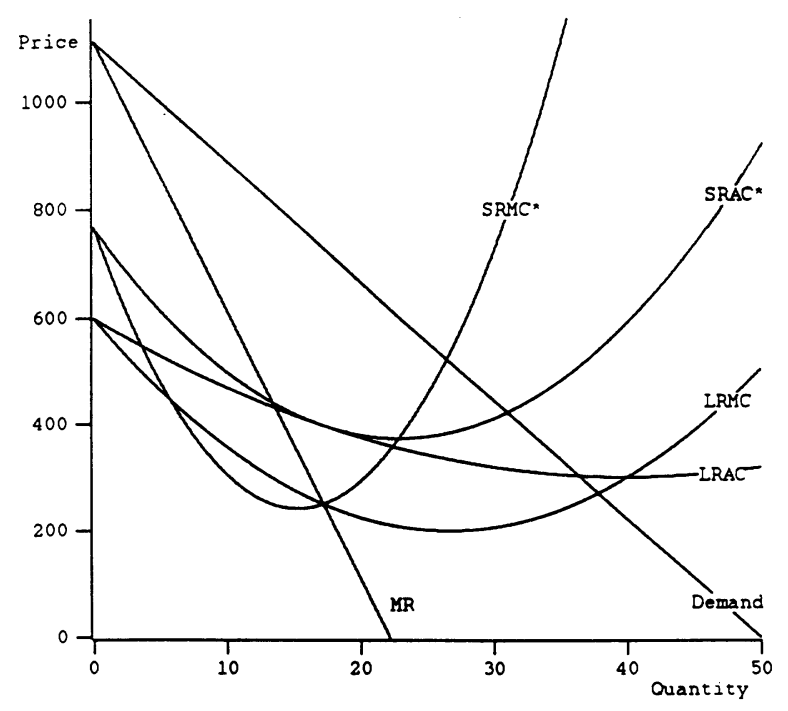

Figure 3. Monopolist in Market B: A Continuous Approximation

by each model is listed. The logic of each of these models justifies the nature and potential reasons for inefficiencies.

\section{Natural Monopoly (Classical)}

The classic model is natural monopoly. According to this model, because of the existence of economies of scale, competition will lead to the existence of a monopoly. All other sellers will participate in market $\mathrm{A}$. This monopoly facing the market demand curve will choose the profit maximizing value of variables without regard to the effect that this action might have on the actions of other sellers, such as their proclivity to enter market $\mathrm{B}$. That is, where $P=D(x)$ is the market demand function and long-run costs are $C(x, s(x))$ the monopolist sets the value of the variables to

$$
\underset{x}{\operatorname{maximize}}[D(x) x-C(x, s(x))]
$$

For the parameters of the experiment the solution is a price of 684 , a quantity equal to 17 , a scale of plant of size $M$ and a profit of 4841 in francs. These can be read from the table. Figure 3 demonstrates the model. For convenience the continuous model, which is only an approximation of the underlying parameters, is used in the figure. The accurate predictions based on the discrete environment are in Table IV.

\section{Tacit Collusion}

Collusion models are very numerous depending upon the complexity of the agreement that can be enforced. It is assumed here that collusion would lead to choices of variables that are good from the seller's point of view. We presume that the values would be something between Cournot and monopoly and that the volume would be similarly restricted. 
Table IV. Experimental Results: Average Transaction Prices, Number of Entrants, Volumes, Efficiencies

\begin{tabular}{|c|c|c|c|c|c|c|c|c|c|c|c|c|c|c|c|c|c|c|}
\hline \multirow[b]{3}{*}{ Period } & \multicolumn{6}{|c|}{061191} & \multicolumn{6}{|c|}{062791} & \multicolumn{6}{|c|}{071891} \\
\hline & \multicolumn{2}{|c|}{ A } & \multicolumn{2}{|c|}{ B } & \multirow[b]{2}{*}{$N$} & \multirow[b]{2}{*}{ Eff. } & \multicolumn{2}{|c|}{ A } & \multicolumn{2}{|c|}{ B } & \multirow[b]{2}{*}{$N$} & \multirow[b]{2}{*}{ Eff. } & \multicolumn{2}{|c|}{ A } & \multicolumn{2}{|c|}{ B } & \multirow[b]{2}{*}{$N$} & \multirow[b]{2}{*}{ Eff. } \\
\hline & $\bar{P}$ & Vol. & $\bar{P}$ & Vol. & & & $\bar{P}$ & Vol. & $\bar{P}$ & Vol. & & & $\bar{P}$ & Vol. & $\bar{P}$ & Vol. & & \\
\hline 1 & 717 & 22 & 325 & 30 & 5 & $92 \%$ & 584 & 25 & 412 & 26 & 3 & $83 \%$ & 697 & 21 & 403 & 29 & 4 & $78 \%$ \\
\hline 2 & 691 & 21 & 312 & 31 & 3 & $92 \%$ & 727 & 20 & 437 & 26 & 5 & $88 \%$ & 704 & 21 & 351 & 30 & 5 & $85 \%$ \\
\hline 3 & 696 & 19 & 325 & 30 & 2 & $92 \%$ & 696 & 21 & 402 & 30 & 2 & $89 \%$ & 682 & 21 & 350 & 30 & 2 & $98 \%$ \\
\hline 4 & 685 & 21 & 324 & 31 & 2 & $97 \%$ & 709 & 21 & 387 & 31 & 4 & $94 \%$ & 693 & 21 & 340 & 28 & 3 & $93 \%$ \\
\hline 5 & 691 & 21 & 322 & 31 & 3 & $97 \%$ & 702 & 21 & 355 & 30 & 2 & $96 \%$ & 701 & 21 & 324 & 31 & 3 & $97 \%$ \\
\hline 6 & 703 & 21 & 315 & 31 & 4 & $95 \%$ & 701 & 23 & 339 & 32 & 2 & $95 \%$ & 703 & 21 & 319 & 31 & 2 & $98 \%$ \\
\hline 7 & 696 & 21 & 323 & 31 & 2 & $99 \%$ & 702 & 21 & 330 & 31 & 4 & $95 \%$ & 696 & 21 & 319 & 31 & 2 & $99 \%$ \\
\hline 8 & 700 & 21 & 320 & 31 & 2 & $99 \%$ & 699 & 23 & 324 & 33 & 2 & $95 \%$ & 697 & 21 & 318 & 31 & 3 & $97 \%$ \\
\hline 9 & 698 & 21 & 321 & 31 & 1 & $100 \%$ & 696 & 22 & - & 0 & 0 & $40 \%$ & 694 & 20 & 330 & 31 & 1 & $98 \%$ \\
\hline 10 & 701 & 19 & 400 & 28 & 2 & $93 \%$ & 698 & 21 & 330 & 30 & 3 & $96 \%$ & 696 & 23 & 325 & 31 & 2 & $96 \%$ \\
\hline 11 & 691 & 21 & 350 & 30 & 3 & $72 \%$ & 700 & 21 & 326 & 31 & 3 & $97 \%$ & 696 & 21 & 320 & 31 & 3 & $97 \%$ \\
\hline 12 & 698 & 21 & 345 & 28 & 3 & $90 \%$ & 701 & 21 & 324 & 33 & 4 & $95 \%$ & 696 & 21 & 321 & 31 & 1 & $100 \%$ \\
\hline 13 & 698 & 21 & 330 & 31 & 3 & $97 \%$ & 700 & 21 & 335 & 30 & 2 & $98 \%$ & 639 & 21 & 319 & 27 & 2 & $85 \%$ \\
\hline 14 & 700 & 21 & 335 & 31 & 2 & $99 \%$ & 699 & 22 & 325 & 31 & 3 & $95 \%$ & 696 & 21 & 330 & 31 & 1 & $98 \%$ \\
\hline 15 & 702 & 24 & - & 0 & 3 & $32 \%$ & 700 & 22 & 330 & 31 & 3 & $95 \%$ & 697 & 21 & 328 & 31 & 3 & $97 \%$ \\
\hline 16 & 700 & 21 & 328 & 32 & 2 & $92 \%$ & 700 & 21 & 326 & 31 & 3 & $97 \%$ & 695 & 21 & 324 & 33 & 3 & $97 \%$ \\
\hline 17 & 700 & 21 & 327 & 31 & 2 & $99 \%$ & 700 & 21 & 327 & 31 & 2 & $99 \%$ & 700 & 21 & 403 & 19 & 3 & $71 \%$ \\
\hline 18 & 700 & 22 & 326 & 31 & 2 & $97 \%$ & 700 & 21 & 325 & 31 & 2 & $97 \%$ & 697 & 23 & & 0 & 3 & $34 \%$ \\
\hline 19 & 701 & 21 & 323 & 31 & 2 & $94 \%$ & 691 & 19 & 437 & 26 & 1 & $93 \%$ & 697 & 21 & 321 & 31 & 2 & $99 \%$ \\
\hline AV. & 698 & 21 & 331 & 29 & 2.5 & $91 \%$ & 695 & 21 & 356 & 29 & 2.6 & $91 \%$ & 694 & 21 & 336 & 28 & 2.4 & $90 \%$ \\
\hline
\end{tabular}

\section{Cournot Models}

Cournot models are all derived from the same general principles. Each competitor evaluates the market as if the quantity offered by the other sellers is a constant and the resulting market price is that determined by the sum of the quantities offered by sellers. For insights about the structure of these models, especially in the presence of non convexities as in the case with economies of scale, see Novshek [3, 61-70; 4].

Application of the class of models to any real market, especially the ones created for these experiments, might be met with three a priori criticisms/qualifications. First, the Cournot solutions to the technical problems are generally not unique. Typically, both symmetric solutions in which all firms act identically and asymmetric solutions, in which some firms are larger than others, exist. The symmetric solutions and those asymmetric solutions that have been identified and seem plausible have been included in Table III. The second qualification is that the principles that might govern entry into a market are not systematically integrated (unless lack of entry is treated as part of an asymmetric solution) into the analysis. For this reason, a special treatment of Cournot models, under a heading called monopolistic competition, is included. The third criticism is derived from the nature of the market structure itself. Agents in these markets post a price and a quantity. There is every reason to assume that the seller with the lowest price will sell all units that the seller offers, up to the demand function limits. The hypothesis that the quantity sold by other sellers remains constant, will almost certainly be violated. Thus, the structure of the decision problem might appear to resemble that of the Bertrand theory, more than Cournot, depending upon how the posted quantity is treated in the analysis. 


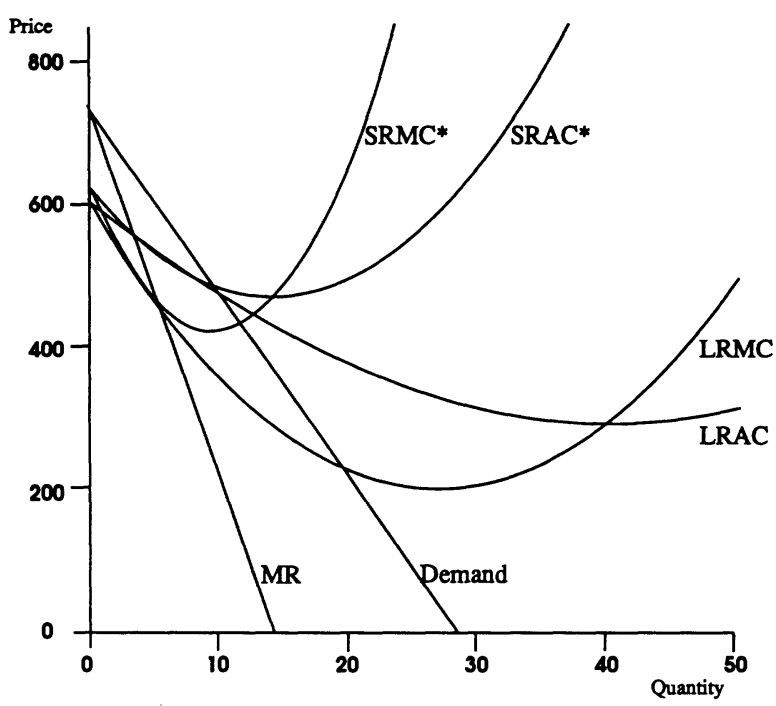

Figure 4. Quadopolist in Market B: A Continuous Approximation

All of the criticisms/qualifications are derived in part from the fact that the Cournot model is incomplete as a theory. It is silent about the nature of the price determination process. If sellers (or buyers) are supposed to be involved in price determination, then some sort of explicit coordination device must exist that guides sellers to settle on the same price, and guides buyers so that sellers share market volume in a Cournot fashion. Instead of dealing with all of this complexity, the Cournot model relies only on axioms typical of game theoretic representations of markets that assert that only one price exists, and further asserts that the one price is determined by the law of supply and demand once sellers' quantity choices are given. Nevertheless, Cournot models have broad experimental support and must be taken seriously in any environment until the data suggest otherwise.

The Cournot solutions for duopoly and for triopoly are also in Table III. Notice that the price predicted is 609 and then becomes 600 , regardless of the number of firms. Of course, firm size must decrease as the number of firms increases. This means that the scale of plant chosen by firms must be smaller under triopoly than under duopoly.

\section{Monopolistic Competition}

The classical model of monopolistic competition is interpreted as a four firm Cournot market. Scale of plants are small in the equilibrium and the opportunity cost of 300 francs $(\$ 1.80)$ is barely covered by the 351 profit. Entry of another firm would force the profits to levels below the opportunity costs. In the table the Cournot equilibrium profits for quintopoly, a fifth firm, are less than the 300 francs opportunity cost for entering the B market. Again, notice from the table that the price predictions are the same, regardless of the number of firms.

In Figure 4 is shown a representative firm in the four firm equilibrium. The background shows the market demand function. The costs graphs are from the continuous approximation of costs given by equation (4). 


\section{Contested Markets}

The contestable market literature has motivated researchers to look for two different types of phenomena in experimental data. The possible phenomenon are called "models" here, but they operate more like statements that characterize the extremes of what one might expect in data. Of course, those extremes and the relative tendencies toward them contain potentially useful information.

Perfectly Contested Market (Competitive) Equilibrium. This is the case in which only one seller exists in the market. The seller produces at a price and output that leaves price equal to average cost, including opportunity cost. The profits in market A and market B would be the same (thereby justifying the use of the term "competitive"). As indicated in the table, the price of the single entrant would be 325 ; volume would be 31 ; scale of plant would be $W$, and the other six sellers would be in market A. The relationships are in Figure 3.

Without side payments, such as a subsidy to compensate a firm for losses, and a completely different institutional arrangement, such as marginal cost pricing, or the incentive compatible equivalent, average cost pricing might be the best that can be expected from a consumer's point of view. It is used as a measure for 100 percent efficiency.

Over-Contested Market Equilibrium. This model postulates that the price and quantities sold would be the same as the perfectly contested outcome above. The only difference is the number of firms that have decided to enter. Previous experiments have defined this model to predict that all of the potential firms enter. Obviously, the plausibility of such phenomena would a priori seem low but this model is included as a benchmarker for completeness. The number, 5 , is taken to be the maximum that could leave market $\mathrm{A}$ and still have it behave competitively.

\section{Unstable ("Bertrand")}

We do not know the equilibrium of the Bertrand model of these experimental markets. Presumably it involves some sort of mixed strategy. In the data this would appear as a type of variability in prices. At this point the model is included for completeness and to draw attention to the possibility that the data might not exhibit any type of monotone convergence property. It is also included to draw attention to the fact that the literature contains suggestions about how such variability phenomena might be modeled should it be observed.

\section{Market Collapse (Type 1)}

Entry into the contested market will involve a cost. The possibility of out-of-pocket losses also exists. Since there are no mechanisms for coordinating entry, sellers might all decide to operate only in the A market. Under such a circumstance the supply in B would be zero. The market would have collapsed. Type 1 collapse is the case when no firm enters the B market.

\section{Market Collapse (Type 2)}

The second type of collapse can occur when more than one firm decides to enter but all cancel leaving no one to supply the market. This is a type of coordination failure which can occur because the decisions to cancel market $\mathrm{B}$ offers are made simultaneously. 


\section{Results}

The central results are easy to state. The contestable markets model is the most accurate of those considered. After a brief review of the data, the discussion turns to making clear the strength of this central proposition. Following the main results, the remainder of this section is devoted to a discussion of a series of five observations about both individual and systems behavior.

A typical price time series for both markets are shown in Figures 5 and 6 . Figure 5 contains the time series for market A, and Figure 6 contains the time series for market B. Vertical lines separate periods. The measure of time differs in the two figures. In market $A$ the measure is seconds. In market B the measure is the number of events (e.g., asks, contracts) because the high speed with which events occur in clock time make them indistinguishable, given the units (seconds) in which clocktime is measured.

The horizontal lines in the figures show the price predictors for various models. The top line is the monopoly price. The second line is the price predicted by all Cournot and monopolistic competition models. The bottom line is the "competitive" price predicted by the contestablemarket model. Contracts are indicated by circles in both the A market and the B market; and in market B the prices posted by sellers are displayed by small triangles. Cancellations in the B markets are not shown, but in most cases all sellers in the B market canceled, except the seller with the lowest posted price.

Figure 7 contains the price and volume data pooled across all experiments. Each dot represents a period in one of the three experiments. The market demand function and the predictions of selected models are also shown in the figure.

The visual impressions are that prices converged to the competitive equilibrium in market $\mathrm{A}$ and that prices converged to the one predicted by the contestable-market model in market B. These visual impressions are essentially correct. The first results reported in this section make the nature of the data that support these impressions precise.

The first result is a traditional statement intended to prevent any misconceptions about what is being reported. Sometimes experimental data are predicted by models in an accurate statistical sense. However, in most cases none of the models are statistically accurate. The first result makes clear that these models contain unanticipated and unexplained errors and, thereby, sets the stage for all subsequent analysis.

RESULT 1. All models can be rejected as a statistically accurate representation of the data.

Support. All models are static equilibrium models. However, the data for the B markets, such as the one contained in Figure 6, exhibits an obvious type of convergence pattern which is not captured by any of the models, even if a random error term is added. In the absence of additional theory appended to the models to take care of the dynamics, the models are rejected.

The second result is perhaps the central result of the paper. It states that the contestable market theory is the one best supported by the data.

RESULT 2. After the first six periods, all relevant economic variables (prices, volumes, profits, scale of plant choices, and efficiencies) are closer to the predictions of the two contestable market models than to the predictions of any other model.

Support. Each of the variables will be discussed in order. All models predict competitive behavior in the A markets. The competitive price is 700 and the volume is 21 . In 51 of the 57 


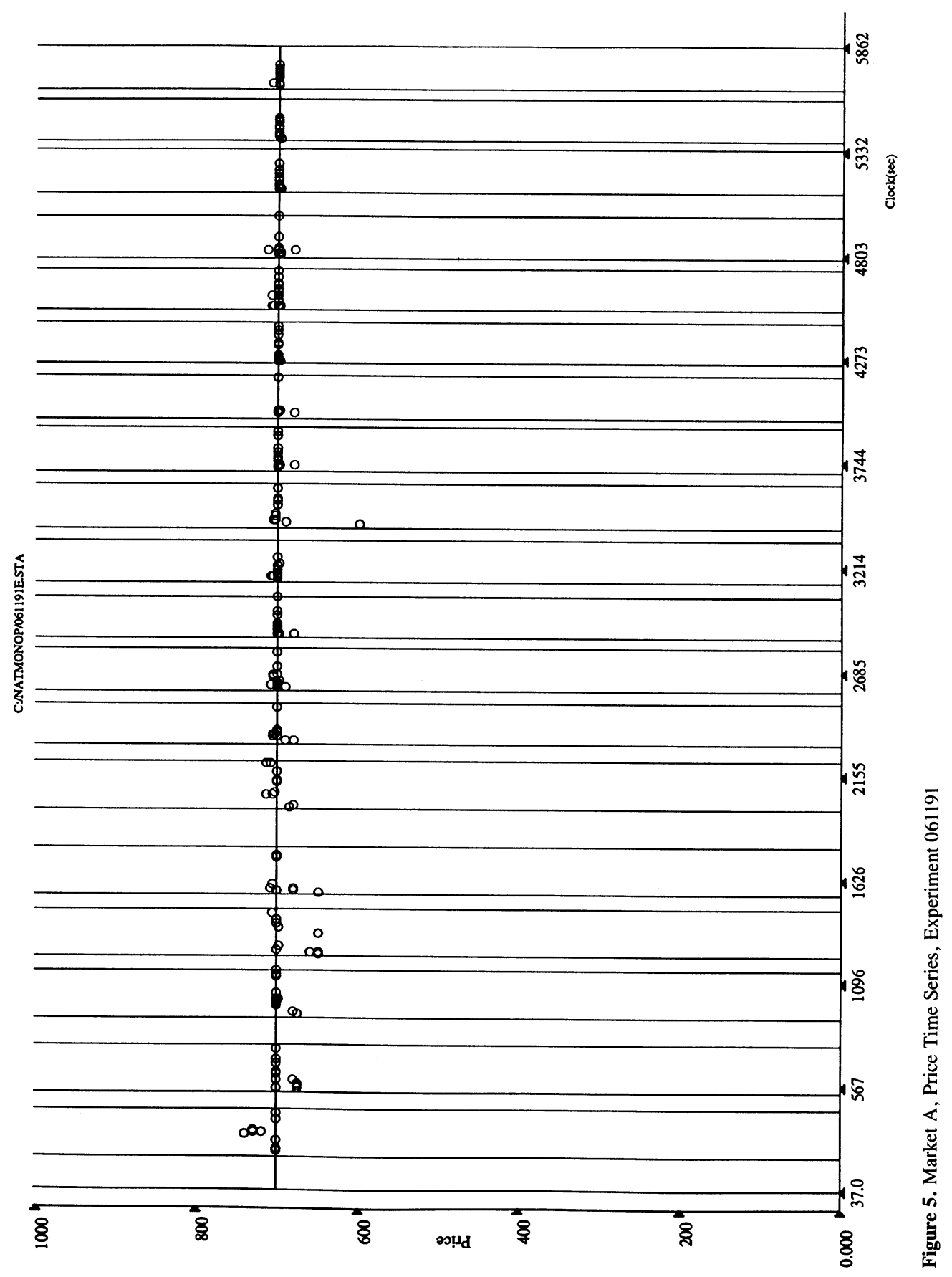




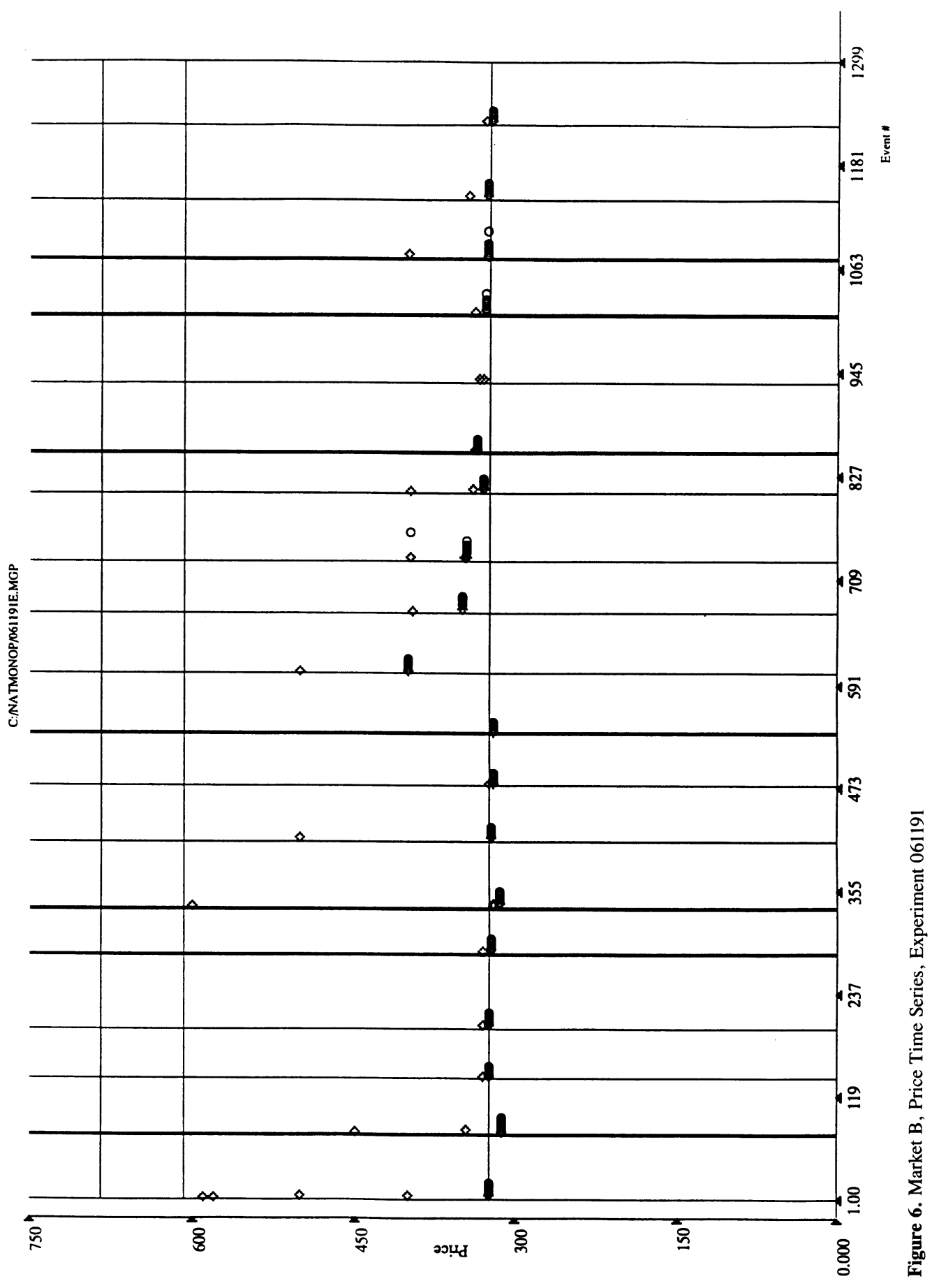




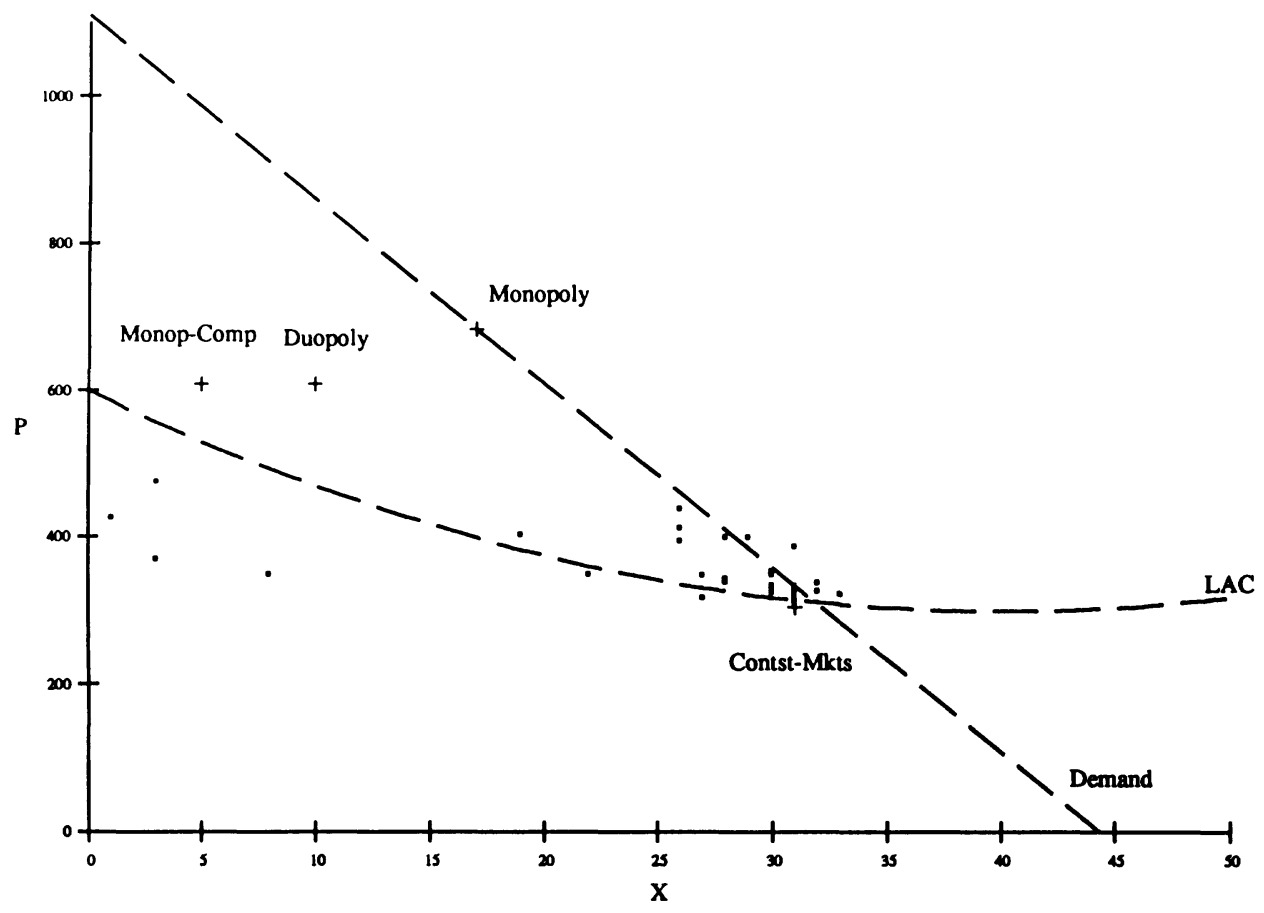

Figure 7. Period Prices and Quantities, All Periods, All Experiments

periods of all experiments the average price of the period was within 10 francs $(6$ cents for sellers and .75 of a cent for buyers) of the competitive equilibrium. In 56 of these periods the volume was within 3 units of the 21 predicted and in 41 periods the volume was exactly 21 units. The relevant data are in Table IV. Since the price and volume in the A markets behaved substantially as predicted by all models, the relevant comparisons are all in the B markets.

In the $\mathrm{B}$ markets prices and volumes tended to be closer to the contestable market models than any of the others. In 41 of the 57 periods, prices were within 10 francs of the price predicted by the contestable-market models (325). In no period was the price within 10 francs of the price predicted by the natural monopoly model (684), and in no period was the price within 10 francs of the price predicted by any Cournot model (609). The count comes directly from the data in Table IV and the predictions in Table III. Similarly, the volume was within three units of the contestable market prediction (31) in 49 of the 57 periods. It was never that close to the prediction of the natural monopoly model (17), and it was never within three units of the predictions of the Cournot models (20). Price and market volume figures support the contestable-market model over the others.

Volume of individual firms further support the contestability model over the Cournot models and the monopolistic competition models which, because of symmetry assumptions, predict that all B market entrants will have the same volume. In 53 of the 57 periods no more than one firm had positive sales in the B market. Thus, in 53 of 57 periods the data support contestability over monopolistic competition. In none of these three periods in which more than one firm made B market sales, was the distribution volumes near equality as predicted by the symmetric game models. As will be implicit in the discussions below, sellers that chose to enter the B market did not limit their quantities as required by the Cournot model and as they could have done under the procedures. 
In market B profit levels predicted by competing models are in Table III. Profits should be at, or above 300 , which is the (nearly) certain profit that can be obtained for participation in market A. Actual profits are in Table V,A. The listing of actual profits of sellers in market B are in Table V,B. The "active" firms referenced in the table are those that did not cancel their posted offer after they had seen the offers of other sellers. Shown also is the number of sellers that entered the B market at the beginning of the period.

Consider only the last four periods of the experiments after some level of equilibration has been achieved. The average profit of the firms that sell units over all three experiments is 451.6 francs per period. The average profit of all entrants is 184.0 francs per period. Thus, the average profit of sellers who entered market B is closer to the 302 predicted by the perfectly contested model than to the prediction of any other model, except quintopoly, which can be rejected since the number of sellers was always less than five. Consideration of more periods does not change this conclusion. In fact, the conclusion is only reinforced. The average profit earned per period by all entrants in market B, considering period 3 and later, for the three experiments was 29.4 francs, 279.0 francs, and 74.2 francs, respectively, far below that predicted by any model except quintopoly.

The frequency of scale of plant choices is contained in Table VI. Only three choices are at scale levels (D, E, G, and M) predicted by any of the alternative models to the contested market model. The contested market model predicts scale $W$, which is the mode of choices of sellers (41 choices out of 146 total). Over 40 percent of all choices are within one level of that predicted by the contestable-market model. The small mode at scale $K$ is interesting because scale $K$ was the example used in the instructions to illustrate the nature of costs.

Efficiency levels are reported in Table IV. The average efficiency level for the three experiments is $.91, .91$, and .90 , which is much closer to the .94 predicted by the over-contested market model than it is the efficiency predicted by natural monopoly (80\%), duopoly (76\%), triopoly $(70 \%)$, monopolistic competition $(67 \%)$, or market collapse $(41 \%)$. On average, the perfectly contested model is a better predictor of efficiency than any of the noncontested models.

In all dimensions the two contestable market theories are better predictors than the alternative models. If one is forced to choose between the perfectly-contested model and the over-contested model the choice will be the former. The average number of entrants per period is 2.56 , which is closer to the one predicted by the perfectly contested model than the five predicted by the over-contested model.

The next five observations focus on aspects of strategic behavior and on system behavior. The first four of the observations are related to individual behavior and the strategies that individuals employ. The fifth observation is a summary property of the system as a whole.

Observation 1 suggests that people bias their choices of prices in favor of those divisible by 5 and that individual strategies exhibit a degree of modification to take advantage of the underlying bias. For example, knowing about this bias, perhaps even in their own behavior, people sometimes reduce their own price by a unit. That is, rather than quote a price of 325 an individual might quote 324 ; or a 330 quotation would be modified downward to 329 rather than, say, increased to 331 .

OBSERVATION 1. Price choices are asymmetrically distributed downward around numbers that end in 0 or 5 .

Support. Actual prices ending in 0 or 5 accounted for a large percentage of choices (71 out of 146). Of the two, prices ending in 0 were the most common, occurring 50 times. Prices in a 


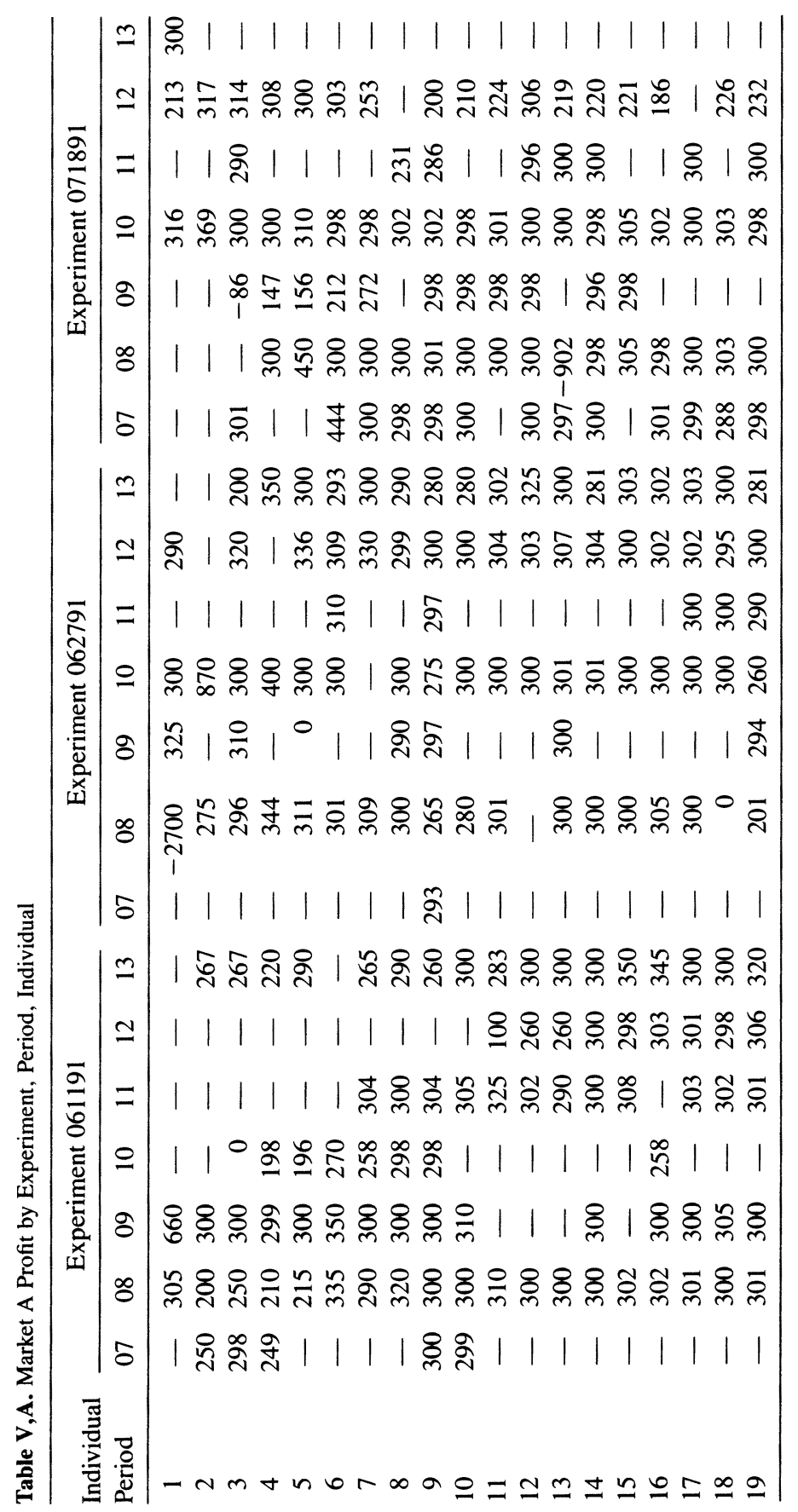


Table V,B. Market B Volume and Profit, by Individual, by Period

\begin{tabular}{|c|c|c|c|c|c|c|c|c|c|c|c|c|c|c|}
\hline \multirow{3}{*}{$\begin{array}{l}\text { Indi- } \\
\text { vidual } \\
\text { Period }\end{array}$} & \multicolumn{14}{|c|}{ Experiment 061191} \\
\hline & \multicolumn{2}{|c|}{07} & \multicolumn{2}{|c|}{08} & \multicolumn{2}{|c|}{09} & \multicolumn{2}{|c|}{10} & \multicolumn{2}{|c|}{11} & \multicolumn{2}{|c|}{12} & \multicolumn{2}{|r|}{13} \\
\hline & Vol. & Profit & Vol. & Profit & Vol. & Profit & Vol. & Profit & Vol. & Profit & Vol. & Profit & Vol. & Profit \\
\hline 1 & 0 & 0 & & & & & 30 & 120 & 0 & 0 & 0 & 0 & 0 & 0 \\
\hline 2 & & & & & & & 31 & -194 & 0 & 0 & 0 & 0 & & \\
\hline 3 & & & & & & & & & 0 & 0 & 30 & 180 & & \\
\hline 4 & & & & & & & & & 31 & 271 & 0 & 0 & & \\
\hline 5 & 0 & 0 & & & & & & & 31 & 209 & 0 & 0 & & \\
\hline 6 & 31 & -101 & & & & & & & 0 & 0 & 0 & 0 & 0 & 0 \\
\hline 7 & 31 & 240 & & & & & & & & & 0 & 0 & & \\
\hline 8 & 0 & 0 & & & & & & & & & 31 & 147 & & \\
\hline 9 & & & & & & & & & & & 31 & 178 & & \\
\hline 10 & & & & & & & 28 & 2016 & & & 0 & 0 & & \\
\hline 11 & 22 & -1166 & & & 8 & -2936 & 0 & 0 & & & & & & \\
\hline 12 & 0 & 0 & & & 28 & 504 & 0 & 0 & & & & & & \\
\hline 13 & 31 & 457 & & & 0 & 0 & 0 & 0 & & & & & & \\
\hline 14 & 31 & 612 & & & & & 0 & 0 & & & & & & \\
\hline 15 & 0 & 0 & & & 0 & 0 & 0 & 0 & & & & & & \\
\hline 16 & 0 & 0 & & & & & & & 32 & 480 & & & & \\
\hline 17 & 31 & 364 & & & & & 0 & 0 & & & & & & \\
\hline 18 & 0 & 0 & & & & & 31 & 333 & & & & & & \\
\hline 19 & 0 & 0 & & & & & 31 & -612 & & & & & & \\
\hline
\end{tabular}

\begin{tabular}{|c|c|c|c|c|c|c|c|c|c|c|c|c|c|c|}
\hline \multirow{3}{*}{$\begin{array}{l}\text { Indi- } \\
\text { vidual } \\
\text { Period } \\
\end{array}$} & \multicolumn{14}{|c|}{ Experiment 062791} \\
\hline & \multicolumn{2}{|c|}{07} & \multicolumn{2}{|c|}{08} & \multicolumn{2}{|c|}{09} & \multicolumn{2}{|c|}{10} & \multicolumn{2}{|c|}{11} & \multicolumn{2}{|c|}{12} & \multicolumn{2}{|r|}{13} \\
\hline & Vol. & Profit & Vol. & Profit & Vol. & Profit & Vol. & Profit & Vol. & Profit & Vol. & Profit & Vol. & Profi \\
\hline 1 & 26 & 1950 & & & & & & & 0 & 0 & & & & ) \\
\hline 2 & 26 & 2600 & & & 0 & 0 & & & 0 & 0 & 0 & 0 & 0 & ) \\
\hline 3 & 1 & -456 & & & & & & & 29 & 2023 & & & & \\
\hline 4 & 31 & 2069 & & & 0 & 0 & & & 0 & 0 & 0 & 0 & 0 & \\
\hline 5 & 0 & 0 & & & & & & & 30 & 900 & & & & \\
\hline 6 & 32 & 736 & & & 0 & 0 & & & & & & & & \\
\hline 7 & 0 & 0 & & & 0 & 0 & 0 & 0 & 31 & 364 & & & & \\
\hline 8 & 0 & 0 & & & & & & & 33 & 239 & & & & \\
\hline 9 & & & & & & & & & & & & & & \\
\hline 10 & 0 & 0 & & & 0 & 0 & & & 30 & 330 & & & & \\
\hline 11 & 0 & 0 & & & 0 & 0 & & & 31 & 240 & & & & \\
\hline 12 & 0 & 0 & 0 & 0 & 33 & 388 & & & 0 & 0 & & & & \\
\hline 13 & 0 & 0 & & & & & & & 30 & 480 & & & & \\
\hline 14 & 0 & 0 & & & 31 & 209 & & & 0 & 0 & & & & \\
\hline 15 & 0 & 0 & & & 31 & 364 & & & 0 & 0 & & & & \\
\hline 16 & 0 & 0 & & & 31 & 333 & & & 0 & 0 & & & & \\
\hline 17 & 0 & 0 & & & 31 & 364 & & & & & & & & \\
\hline 18 & 31 & 256 & & & 0 & 0 & & & & & & & & \\
\hline 19 & 26 & 2600 & & & & & & & & & & & & \\
\hline
\end{tabular}


Table V,B. Continued

\begin{tabular}{|c|c|c|c|c|c|c|c|c|c|c|c|c|c|c|c|}
\hline \multirow{3}{*}{$\begin{array}{l}\text { Indi- } \\
\text { vidual } \\
\text { Period }\end{array}$} & \multicolumn{15}{|c|}{ Experiment 071891} \\
\hline & \multicolumn{2}{|c|}{07} & \multicolumn{2}{|r|}{08} & \multicolumn{3}{|c|}{09} & \multicolumn{2}{|c|}{10} & \multicolumn{2}{|c|}{11} & \multicolumn{2}{|c|}{12} & \multicolumn{2}{|r|}{13} \\
\hline & Vol. & Profit & Vol. & Profi & Vol & & Profit & Vol. & Profit & Vol. & Profit & Vol. & Profit & Vol. & Profit \\
\hline 1 & 26 & 988 & ( & o & 0 & 3 & -1798 & & & 0 & 0 & & & & \\
\hline 2 & 3 & -1048 & 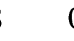 & o & 0 & 0 & 0 & & & 0 & 0 & & & 27 & 263 \\
\hline 3 & & & , & 0 & 0 & & & & & & & & & 30 & 870 \\
\hline 4 & 28 & 112 & & & & & & & & 0 & 0 & & & 0 & 0 \\
\hline 5 & 0 & 0 & & & & & & & & 31 & 178 & & & 0 & 0 \\
\hline 6 & & & & & & & & & & 31 & 23 & & & 0 & 0 \\
\hline 7 & & & & & & & & & & 31 & 116 & & & 0 & 0 \\
\hline 8 & & & & & & 0 & 0 & & & & & 0 & 0 & 31 & 85 \\
\hline 9 & & & & & & & & & & & & & & 31 & 302 \\
\hline 10 & & & & & & & & & & 31 & 302 & & & 0 & 0 \\
\hline 11 & 0 & 0 & & & & & & & & 31 & 132 & & & 0 & 0 \\
\hline 12 & & & & & & & & & & & & & & 31 & 178 \\
\hline 13 & & & & & & & -952 & & & & & & & 0 & 0 \\
\hline 14 & & & & & & & & & & & & & & 31 & 302 \\
\hline 15 & 0 & 0 & & & & & & & & 31 & 395 & & & 0 & 0 \\
\hline 16 & & & & & & & 487 & & & 0 & 0 & & & 0 & 0 \\
\hline 17 & & & & & & 0 & 0 & & & & & 19 & 185 & 0 & 0 \\
\hline 18 & & & & & & 0 & 0 & & & 0 & 0 & & & 0 & 0 \\
\hline 19 & & & & & & 0 & 0 & & & & & & & 31 & 178 \\
\hline
\end{tabular}

neighborhood, \pm 1 , around 0 and 5 , were also asymmetrically distributed, with the two numbers 9 and 4 being preferred to the two numbers 1 and 6 by a margin of 22 to 14 . A hypothesis of equal probability can be rejected at .01 level of confidence.

The second observation suggests that behavior does not reflect the belief that the behavior of others is independently random with probabilities represented by the relative frequencies of choices. Table VII shows the relative frequencies with which price choices were made, together with the expected profit that would result from various pricing decisions, given that the choices of others are drawn with probabilities equal to the frequencies in the table. If the system was at a Nash equilibrium, then the expected profit would be the same for all price choices.

OBSERVATION 2. Pricing strategies are not Nash responses given the relative frequency of prices that was observed.

Support. Consider the potential ask prices in Table VII. The high prices in the neighborhood of 360 and 385 would yield a profit of 150 percent or greater of the lower prices.

The third observation is that scale choices of agents are optimal given actual volumes sold by sellers. This is particularly interesting because the scale choices are not optimal given the quantities offered for sale by sellers. Recall that sellers entering market B chose a scale, a price, and a quantity offered. The observation is that the scale choice suggests that sellers (correctly) expected to sell the market demand quantity but they offered a little more than that expectation in hope that the volume would be (possibly accidentally) higher.

OBSERVATION 3. The scale chosen by agents tends to be optimum given the actual quantity sold. Actual quantity sold tends to equal induced market demand given the quote of price. Quantity 
Table VI. Frequency of Scale of Plant Choice in All Three Experiments, All Periods

\begin{tabular}{ccl}
\hline Scale & Number of Choices & \\
\hline A & 3 & \\
B & 0 & \\
C & 3 & Cournot triopoly and more \\
D & 1 & \\
E & 0 & Cournot duopoly \\
F & 0 & \\
G & 1 & \\
H & 0 & \\
I & 1 & \\
J & 1 & \\
K & 9 & \\
L & 0 & \\
M & 1 & \\
N & 0 & \\
O & 3 & \\
P & 1 & \\
Q & 0 & \\
R & 2 & \\
S & 8 & \\
T & 7 & \\
U & 25 & \\
V & 21 & \\
W & 41 & \\
X & 15 & \\
Y & & \\
\hline
\end{tabular}

Table VII. Relative Frequency of Price Choices in Periods beyond the Sixth and Expected Profits of Price Strategy

\begin{tabular}{lcccccc}
\hline Price Range & $\begin{array}{c}\text { Relative Frequency of } \\
\text { Low Price Choices }\end{array}$ & $\begin{array}{c}\text { Posted Price } \\
\text { Strategy }\end{array}$ & $\begin{array}{c}\text { Profit if } \\
\text { Low Price }\end{array}$ & $\begin{array}{c}\text { Prob.* of } \\
\text { Low Price }\end{array}$ & $\begin{array}{c}\text { Expected } \\
\text { Profit }\end{array}$ \\
\hline $318 \leq p \leq 324$ & $19 / 90$ & 0.21 & & & & \\
$325 \leq p \leq 329$ & $22 / 90$ & 0.24 & 325 & 302 & 0.79 & 238 \\
$330 \leq p \leq 334$ & $10 / 90$ & 0.11 & 330 & 457 & 0.54 & 256 \\
$335 \leq p \leq 339$ & $5 / 90$ & 0.07 & 335 & 612 & 0.43 & 257 \\
$340 \leq p \leq 344$ & $4 / 90$ & 0.04 & 340 & 630 & 0.39 & 220 \\
$345 \leq p \leq 360$ & $6 / 90$ & 0.07 & 345 & 780 & 0.33 & 250 \\
$360 \leq p$ & $24 / 90$ & 0.27 & 360 & 1230 & 0.27 & 307 \\
& & & 385 & 1980 & 0.27 & 528 \\
\hline
\end{tabular}

\footnotetext{
*Computed neglecting ties.
}

offered for sale is greater than actual sales and the scale of plant chosen is too small given the quoted quantity.

Support. Figure 8 shows deviations of actual scale chosen from the theoretical optimum scale given the price quoted by the agent. If the seller has the lowest price then the demand function can be used to determine the quantity that will be sold. The quantity to be sold can be used to determine the optimal scale for that quantity. The figure shows deviations from this optimum where 0 indicates the optimum and \pm 1 indicates one letter deviations from the optimum. As can be seen in the figure, the mode of choice is the optimum given the price. 


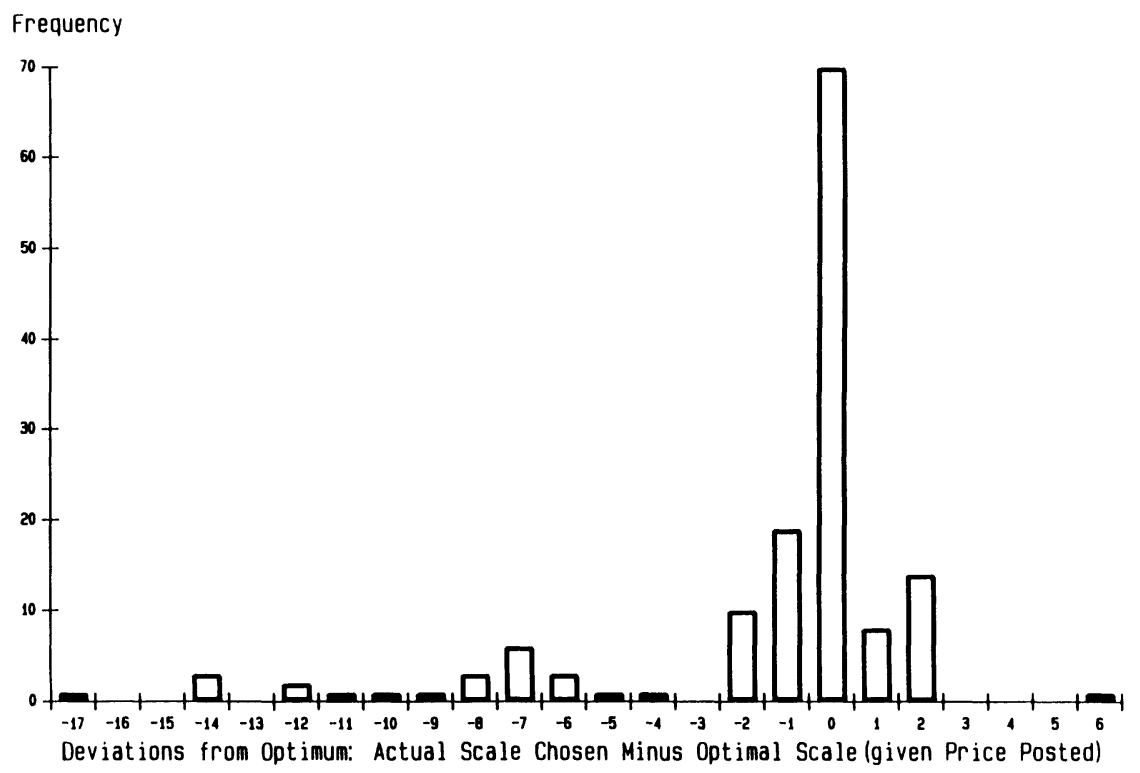

Figure 8. Deviations from Optimum: Actual Scale Chosen Minus Optimal Scale (Given Price Posted)

The same calculation can be made using the quantities offered for sale. Figure 9 shows deviation of scale choice from the optimum given the quantity offered. As can be seen, the scale choices tend to be smaller than this calculation of optimum.

The next observation is that agents specialize in markets. Some agents are always in market A while others have a propensity to enter market B. Table VIII contains for each individual of each experiment, the total number of times during the nineteen periods of the experiment, the number of times the individual entered the B market. For example, the person with identification number 7 in experiment 061191 entered the B market 14 times out of the nineteen periods, while person 8 of that experiment never entered.

OBSERVATION 4. The frequency with which market B is entered is not the same across sellers.

Support. Test the hypothesis that the decisions made by the two individuals with the lowest propensity to enter, were independently drawn from the same distribution as the decisions of the two people with the highest propensity. The hypothesis is rejected at the .001 level of significance.

The final Observation 5 concerns the behavior of the whole market system. As was noted in Result 2, efficiencies are not at $100 \%$ as they should be if both the competitive model and the perfectly contested market were working perfectly to predict behavior. On average, excluding the first periods, the system of both markets is operating at an efficiency level of about $91.3 \%$. While this is much better than the $80 \%$ predicted by the natural monopoly model, or the $41 \%$ predicted by the market collapse model, these two models suggest sources of inefficiency that can be interpreted as the social cost of regulation. If more than one firm happens to enter the market there is an opportunity cost of profits foregone in market A. On the other hand, if there is under entry (no firm enters and sells) an efficiency loss will exist due to the loss of consumer surplus in market $\mathrm{B}$. The observation is that the efficiency loss from these two sources amounts to about $67 \%$ of the $8.7 \%$ average loss in system efficiency (not including the first periods). 


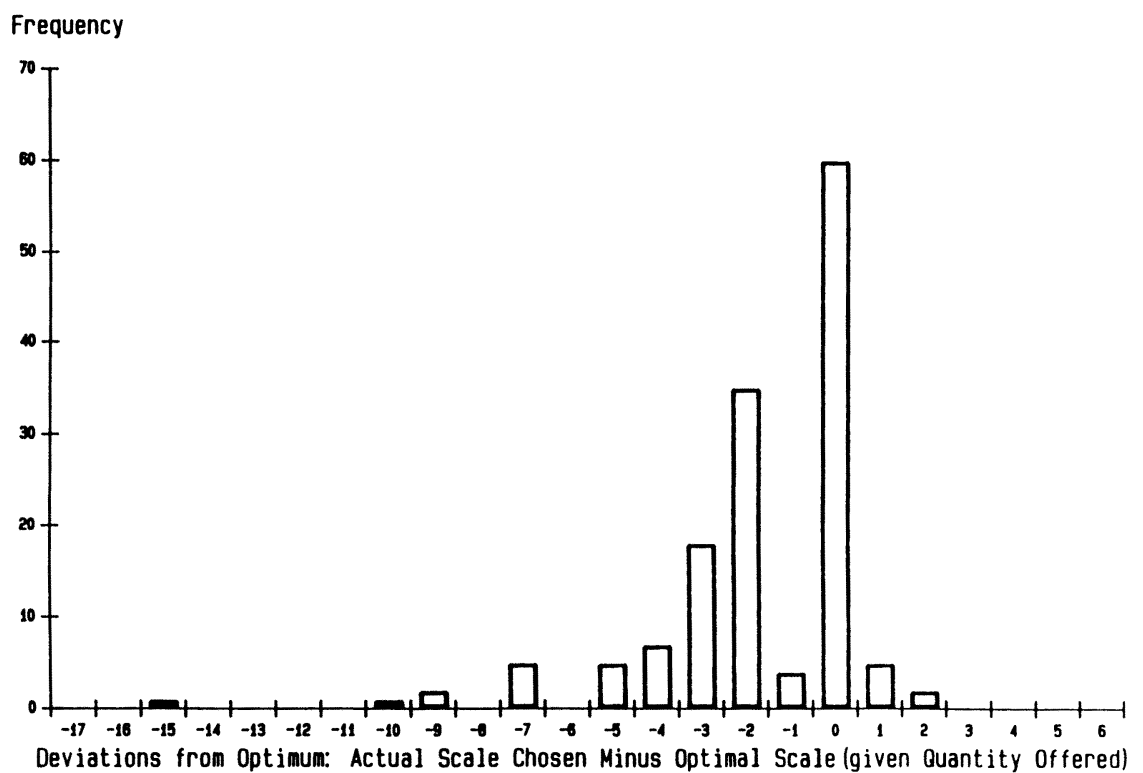

Figure 9. Deviations from Optimum: Actual Scale Chosen Minus Optimal Scale (Given Quantity Offered)

Table VIII. Number of Decisions to Enter the B Market in All Nineteen Periods: By Individual, by Experiment

\begin{tabular}{lrrrrrrr}
\hline & \multicolumn{7}{c}{ Individual Identification Number } \\
\cline { 2 - 8 } Experiment & 7 & 8 & 9 & 10 & 11 & 12 & 13 \\
\hline 061191 & 14 & 0 & 4 & 11 & 7 & 10 & 2 \\
062791 & 18 & 1 & 12 & 1 & 14 & 2 & 2 \\
071891 & 6 & 3 & 8 & 0 & 11 & 2 & 18 \\
\hline
\end{tabular}

OBSERVATION 5. Excluding first periods, efficiency loss due to over entry is about $2.19 \%$ and efficiency loss due to under entry is about $3.32 \%$.

Support. If exactly one firm leaves market A and enters market B the system can operate at $100 \%$ efficiency. This maximum possible efficiency expressed as a function of the number of entrants, $n$ is: maximum possible efficiency $=100-(.01475)(n-1)$ if $n>0$. However, the maximum possible efficiency is .41 if $n=0$. Thus, $(.01475)(n-1)$ is the efficiency loss due to over entry and .59 is the efficiency loss due to no entry (or under entry). Of course, both over entry and under entry can occur at the same time if several firms enter and all cancel their asks and thus sell nothing.

The number of firms that left market $A$ with an intent to enter market $B$ each period of each experiment is contained in Table IV. Application of the formula to the numbers in the table produces for all experiments and for all periods (except the first periods), an average loss of .0219 due to over entry. The table also shows three periods, one in each experiment, in which no units were sold in market B due to no entry either by virtue of leaving market $A$ and canceling (two periods) or by not leaving market A (one period). The efficiency loss averaged over all periods except the first periods, is 0.0332 .

If the efficiency losses identified in Observation 5 are interpreted as the cost of market regulation then the overall average efficiency loss of $8.7 \%$ can be decomposed into an implicit 
regulatory cost of $5.5 \%$ and "other inefficiencies" of $3.2 \%$. Of course, whether or not this is the least expensive regulation possible is not addressed here. The major point is to identify the inefficiency and demonstrate that it can be measured.

Once the "regulatory cost" or "uncoordinated entry cost" is removed, the remaining $3.2 \%$ efficiency loss is of interest. This percentage represents the combined effects of typos, wrong scale choices, inefficiencies due to strategic maneuvering, inefficiencies due to posted prices above average cost, etc. The fact that the combined effect of all sources of inefficiency is small, strongly suggests that, with the exception of uncoordinated entry, the perfectly contested market theory is predicting almost perfectly. That is, the cost expended on this form of regulation has been almost perfect in achieving its desired effect.

\section{Conclusions}

This paper posed a series of questions. First, will increasing returns result in a single seller? Will the single seller charge a monopoly price? If a monopoly price is not charged, do models exist that accurately predict what the price will be?

The answer to the first question is "yes." For the most part, all sales tend to be made by a single agent. This is a particularly interesting result since neither monopolistically competitive or oligopolistic structures tended to evolve, even though they could have. In particular, the data provide no support at all for Cournot models of industrial structure and pricing.

The answer to the second question is "no." Even though sales were almost always by a single seller, monopolistic pricing did not emerge. Instead, the single seller sold at prices near those that would prevail if units were supplied at the lowest average cost that covered the opportunity cost of the supplying firm. The supplying firm chose to operate at a scale of plant and at prices such that consumers paid the lowest possible price subject to the constraint that the supplier did not make a loss. Briefly put, the system behavior was closer to that described by contestable market theory than any of the other models considered.

In some respects, the data here provide strong support for the conclusions drawn from other studies that experimentally examined the possibility of contestability theory. One could have been concerned that the results of other studies might have been due to subject boredom, the linearity of costs, the lack of latitude for monopolistically competitive organizations, etc. The results of this paper demonstrate that such concern about previous results are not well-founded. The fundamental tendencies reported by others were observed after all of the potential explanations were controlled.

To the extent that contestable market theory fell short of accurate predictions, the nature of the failure of contestability theory is interesting. The tendency to enter the "monopolized" market is too great and there is a chance that no one will enter. Firms tended to enter the industry in the hope that the incumbent would try to raise prices to near monopoly levels. Given the behavior of the incumbent, these firms would have been better off participating in alternative economic activity. In a sense, the policing activity was the cost of regulating the incumbent. Aside from this monitoring cost, the system worked substantially as predicted by contestability theory.

Obviously there exist many alternative ways to conduct experiments and check the robustness of the results reported here. Existing theory, especially game theory, is rich with suggestions for further experiments, Shapiro [9, 330-414]. Theoretically, the timing of decisions could switch market behavior between Bertrand and Cournot. Theories of signaling, repeated games, and other 
facets of dynamic rivalry, suggest variables and circumstances that might have dramatic effects on behavior. The message, at this point, seems to be that future research and experimental designs to explore these many possibilities should proceed on the presumption that contestability theory will have considerable exploratory power.

\section{References}

1. Coursey, Don, R. Mark Isaac, M. Luke, and Vernon L. Smith, "Market Contestability in the Presence of Sunk (Entry) Cost." Rand Journal of Economics, Spring 1984, 69-84.

2. Coursey, Don, R. Mark Isaac, and Vernon L. Smith, "Natural Monopoly and Contested Markets: Some Experimental Results." Journal of Law and Economics, April 1984, 91-113.

3. Novshek, William, "Finding All $n$-Firm Cournot Equilibria." International Economic Review, February 1984, $61-70$.

4. - . "On the Competitiveness of Large Cournot Markets." Unpublished manuscript, Purdue University.

5. Plott, Charles R. "A Computerized Laboratory Market System and Research Support Systems for the Multiple Unit Double Auction." Social Science Working Paper no. 783, Pasadena: California Institute of Technology, November 1991

6. - and Peter Gray, "The Multiple Unit Double Auction." Journal of Economic Behavior and Organization, March 1990, 245-58.

7. — and Vernon L. Smith, "An Experimental Examination of Two Exchange Institutions." Review of Economic Studies, February 1978, 133-53.

8. - Alexandre B. Sugiyama, and Gilad Elbaz. "Economies of Scale, Natural Monopoly and Imperfect Competition in an Experimental Market." Social Science Working Paper no. 773, Pasadena: California Institute of Technology, revised February 1994.

9. Shapiro, Carl. "Theories of Oligopoly Behavior," in Handbook of Industrial Organization, vol. 1, edited by R. Schmalensee and R. D. Willig. Amsterdam: Elsevier Science Publishers B.V., 1989, pp. 330-414.

10. Smith, Vernon L. "An Empirical Study of Decentralized Institutions of Monopoly Restraint," in Essavs in Contemporary Fields of Economics in Honor of Emanuel T. Weiler (1914-1979), edited by George Horwich and James P. Quirk. West Lafayette, Indiana: Purdue University Press, 1981, pp. 83-106. 